\title{
A Binary Particle Swarm Optimization Algorithm for Ship Routing and Scheduling of Liquefied Natural Gas Transportation
}

\author{
Amir Karbassi Yazdi $^{1}$, Mohamad Amin Kaviani $^{21}$, Ali Emrouznejad ${ }^{3}$, Hadi Sahebi $^{4}$ \\ ${ }^{1}$ Young Researchers and Elite Club, South Tehran Branch, Islamic Azad University, Tehran, Iran \\ ${ }^{2}$ Department of Electrical and Computer Engineering, KIOS Research and Innovation Center of Excellence, \\ University of Cyprus, Nicosia, Cyprus \\ ${ }^{3}$ Aston Business School, Aston University, Birmingham, UK \\ ${ }^{4}$ School of Industrial Engineering, Iran University of Science \& Technology, \\ Narmak, Tehran, 16846-13114, Iran
}

\begin{abstract}
With the increasing global demands for energy, fuel supply management is a challenging task of today's industries in order to decrease the cost of energy and diminish its adverse environmental impacts. To have a more environmentally friendly fuel supply network, Liquefied Natural Gas (LNG) is suggested as one of the best choices for manufacturers. As the consumption rate of LNG is increasing dramatically in the world, many companies try to carry this product all around the world by themselves or outsource it to third-party companies. However, the challenge is that the transportation of LNG requires specific vessels and there are many clauses in related LNG transportation contracts which may reduce the revenue of these companies, it seems essential to find the best option for them. The aim of this paper is to propose a meta-heuristic Binary Particle Swarm Optimization (BPSO) algorithm to come with an optimized solution for ship routing and scheduling of LNG transportation. The application demonstrates what sellers need to do to reduce their costs and increase their profits by considering or removing some obligations.
\end{abstract}

Keywords: Binary Particle Swarm Optimization, Ship Routing, Scheduling, Transportation, Liquefied Natural Gas, Optimization.

\footnotetext{
${ }^{1}$ Corresponding author: Department of Electrical and Computer Engineering, KIOS Research and Innovation Center of Excellence, University of Cyprus, Nicosia, Cyprus, E-mail: kaviani.mohmmadamin@ucy.ac.cy
} 


\section{Introduction}

\subsection{The significance of the study}

Nowadays, the Liquefied Natural Gas (LNG) consumption rate has grown significantly owing to $\mathrm{CO}_{2}$ emissions of traditional fuels and the related economic concerns (Khalilpour \& Karimi, 2011). The 2005-2030 forecasts show that the LNG consumption rate will increase by approximately $50 \%$. In addition, the LNG market share of the global energy market will increase from $20 \%$ in 2005 to $25 \%$ in 2030 (EIA, 2009). Erstwhile, this market was almost monopoly because LNG production costs were quite high; however, novel technologies have reduced the design and production costs although they are still high for the producers. In addition to price, LNG supply chain requires an effective structure capable of transporting this energy to spot markets; in other words, the transportation system is an important element for having an efficient LNG supply chain (Andersson, Christiansen, \& Fagerholt, 2010). Over short distances, LNG (and the like) can be transferred through pipelines; however, in longer distances (common in most cases), special vessels are safer, more reasonable, and more economical (Grønhaug \& Christiansen, 2009). Accordingly, the importance of maritime transportation in the LNG industry has increasingly attracted attention towards optimizing LNG transportation problems across the seas.

Another noticeable issue is the nature of the LNG transportation contracts which can be either long-term or short-term. The former have less flexibility and often narrow the opportunity of short-term contracting (which is more profitable) while the latter are more flexible and have attracted the attention of the LNG exporters and importers during recent years (Hartley, Mitchell, Mitchell, \& Baker, 2013). As a result, many governments, manufacturing companies, exporters, importers, and transportation companies analyze this most profitable strategy for entering, investing, and competing in the global LNG markets. In signing LNG contracts and setting the articles, both sellers and buyers seek to optimize their costs/benefits.

Investigating literature demonstrate there are a fair number of studies in which various routing and scheduling of LNG shipping and inventory are investigated (Christiansen et al. 2013). For example, Grønhaug et al. (2010) have used branch and price method, Goel et al. (2012) have applied mixed integer programming (MIP) and arc-flow methods, and Goel et al. (2015) have depicted constraint programming to solve LNG issues with inventory routing problem. HalvorsenWeare \& Fagerholt, (2013) have proposed a new model to solve LNG routing and scheduling problems considering inventory and berth constraints and Halvorsen-Weare, Fagerholt, \& 
Rönnqvist, (2013) have analyzed the LNG ship routing and scheduling model in an uncertain environment using a mixed integer linear programming (MILP) solved by simulation-based optimization methods. In another study, Rakke et al. (2011) have applied MIP-based heuristic methods for optimization of LNG transportation. There are also several other similar studies in this domain which shows that researchers and practitioners have paid much attention to such maritime LNG transportation problems as ship routing and scheduling.

\subsection{The objective of the study}

The aim of this study is to present a mathematical model for minimizing the cost of transporting LNG to the destination by ship. As mentioned before, LNG contract can be divided into two categories: short-term and long-term contracts. Most of the contracts are long-term in which all costs are fixed. These costs are inventory, maintenance, the penalty of delay, the penalty of evaporation gas and so on. Hence, fluctuation in cost and price causes negative effects on seller or buyer profits. We have focused on sellers' optimization and so the proposed approach is solved by the seller-oriented approach to minimize the cost of LNG transportation and improve the bargaining power of the seller. An alternative is a buyer-oriented approach which can be developed in a similar manner.

In the current study, the effort has been made to investigate a real-world problem wherein an organization aims at optimizing its LNG shipping transportation operations by considering two new constraints as the probable troubles and a mathematical model has been proposed for the optimization of the ship routing and scheduling decisions on LNG transportation planning. A contribution of this study to the existing literature is that it considers the probability of cargo delivery failure during the transferring process and obliges the seller (in the LNG contract) to send a reserved ship to successfully deliver the cargo to the buyer; the ship maintenance time has also been considered in the model. In LNG transportation contracts, considering a case when a ship cannot deliver the cargo to the destination because of any breakdown problem is a key point that has considerable effects on both the time and money of the contract parties.

Our presented model is flexible due to the usage of both stochastic and deterministic data. In previous studies, most of the scholars have attempted to present ship routing models using deterministic data, or if they have used stochastic data, they have changed them to deterministic data and have not investigated all the possible solutions in a specific stochastic data. This may 
cause losing the chance of finding optimal solutions among uninvestigated local or global solutions. By applying stochastic data, the lowest and highest possible data are considered and the applied algorithm searches for the optimal solution; in other words, all data have a uniform probability for being selected as an optimal solution. Furthermore, utilizing both deterministic and stochastic data reflects more realistic situations. To solve the model, we use a kind of the PSO, BPSO, which is a well-known meta-heuristic method because it addresses computational complexities and in the proposed model we deal with the binary decision variable and stochastic and deterministic data concurrently. This research has extracted its data from Rakke et al. (2011); they are real and are based on the databases of the earlier studies.

The outcomes of this research help LNG buyer/seller companies to make better decisions under real and uncertain conditions and contract parties' managers to decide appropriately before signing any LNG contract. The first significant result of this study is that it helps the committed party (of successfully delivering LNG by maritime facilities) to find out how many reserve ships should be assigned to the hubs of the transportation system and the second is related to considering the ship maintenance costs and the benefits of including this item in the LNG contract in order to make a more proper decision on whether the buyer or the seller is responsible for this unwanted cost. The third finding helps a manager to find out what the suitable number of assigned ships is for each LNG contract party to be included in the contract. In particular, while LNG trader companies deal with more than one contract per a specific time period, their managers need to discover how many ships they should assign to each contract and how to include this issue in their contracts.

\subsection{Contribution and organization of the paper}

This study has several contributions. First, in the investigated LNG ship routing problem, this work has considered the probability of ship drowning and its related costs during the transferring process. Second, in the LNG transport contract, a penalty has been considered for the buyer, if the berth is not available for port operations. The third and the main contribution is to the solution method; BPSO algorithm is applied to solve the NP-hard model. PSO algorithm is one of the methods for solving stochastic data. (Kennedy \& Eberhart, 1995). As the decision variable of the proposed mathematical model is binary, BPSO is used to deal with the stochastic parameters as well as the deterministic ones considering this issue that there are several earlier studies in which applying BPSO method has led to viable solutions for solving optimization problems (i.e Liu and 
Fan, 2009; Yang et al. 2014; Beheshti et al. 2015; Jain et al. 2018). To the best of our knowledge, BPSO has not been previously used for LNG ship routing problem in the literature, and formulating the LNG ship routing is also a significant novelty.

The rest of this paper is structured as follow. Section 2 focuses on reviewing the literature and highlighting the research gap. Section 3 is devoted to describing the studied problem and elaborating on the proposed mathematical model. Section 5 discusses the solution methodology. In Section 6, we provide the results and sensitivity analyses. Finally, conclusions and suggest several ideas for future studies are given in Section 7.

\section{Related works}

\subsection{Optimization in LNG supply chain}

LNG supply chain optimization plays a key role for gas transportation companies to gain more competitive advantages. According to Austbø et al. (2014), although there are plenty of earlier researches in the area of energy supply chain planning, there are still fewer studies in which LNG supply chain optimization problems are investigated considering real constraints. This can be due to the fact that although the use of LNG has some merits, it has also some disadvantages compared with other fuels. For instance, $\mathrm{LNG}$ transportation needs the $\mathrm{LNG}$ to be cooled up to $-163^{\circ} \mathrm{C}$ which requires the considerable budget to build a facility; hence, profit can be a key issue in such cases. While many manufacturers attempt to use LNG for different reasons, some others are concerned about the revenue and cost of this market. This also implies LNG supply chain optimization is a research field that still needs to be further investigated.

Maritime transportation is a leading research area in the LNG supply chain planning. LNG shipping optimization problems are more placed in two main categories. The first group is LNG inventory routing problems which seek for the optimal inventory level of LNG in the origin and destination ports. Some studies like Grønhaug et al. (2010), Goel et al. (2012), Stålhane et al. (2012b), Shao et al. (2015), Zhang et al. (2017) and Zhang et al. (2018) have investigated this kind of problems. The second group investigates the ship routing and scheduling problems of LNG transportation (i.e Rakke et al., 2011; Halvorsen-Weare \& Fagerholt, 2013; Halvorsen-Weare et al., 2013; Mutlu et al., 2016; Koza et al., 2017). The objective of problems in the second group is to develop annual delivery programs (ADP) of LNG transportation. Beside the mentioned categories, there are also a few studies in the literature that have focused on the applications of 
game theory (cooperative and non-cooperative games) in LNG shipping (i.e. Gkonis \& Psaraftis, 2009; Massol \& Tchung-Ming, 2010). Furthermore, in studies such as Berle et al., (2013) and Biobaku et al., (2015), risk analysis tools are also applied in LNG shipping problems. It is noteworthy that, all the mentioned quantitative approaches, have tried to provide cost-effective solutions for both buyers and sellers across the LNG supply chain.

\subsection{Considered restrictions in LNG maritime optimization models}

Mathematical models are among the optimization approaches which has attracted the attention of the LNG ship routing researchers. Reviewing the literature indicates that, in the presented mathematical models for LNG ship routing problems, numerous technical constraints have been considered for making the mathematical models more realistic. Among the considered technical constraints, the terminal inventory is an important element of ship routing problems considering the constant daily rate of evaporating LNG at the storage tanks which deals with the inventory control policy. Some previous studies encompass Halvorsen et al. (2013), Ghiami et al. (2015), Goel et al. (2015), Al-Haidous et al. (2016) and Msakni \& Haouari (2018) have considered this important constraint in their models.

There are also several considered constraints in the optimization models of LNG process design and operations including Berth availability (Halvorsen-Weare \& Fagerholt, 2013; AlHaidous et al., 2016; Andersson et al., 2017; Msakni \& Haouari, 2018), ship travel time (Halvorsen et al., 2013; Agra et al., 2015; Zhang et al., 2017; Msakni \& Haouari, 2018), maintenance (AlHaidous et al., 2016; Msakni \& Haouari, 2018), bunkering requirements (Al-Haidous et al., 2016; Msakni \& Haouari, 2018) and amount and time of delivery (Rakke et al., 2011; Shao et al., 2015; Mutlu et al., 2016; Zhang et al., 2017; Zhang et al., 2018) among other contract constraints.

\subsection{Deterministic versus stochastic optimization algorithms}

Investigating the literature about the characteristics of the optimization models in LNG maritime transportation shows that deterministic, non-deterministic (stochastic) parameters or combination of them are all used in the in earlier studies. The deterministic parameters are considered discrete while stochastic ones are considered as continuous parameters. On the other hand, concentrating on the applied solution methods, in the literature, there are both deterministic and stochastic optimization algorithms which are all utilized to search for the optimal solutions. In the sphere of LNG transportation, applied deterministic optimization algorithms comprise branch-and-price 
(Grønhaug et al. 2010), Branch and bound (Rakke et al. 2011), branch and cut (Andersson et al., 2017), dynamic programming (Stålhane et al. 2012b), sequential quadratic programming (Skaugen et al., 2013) and other algorithms. In addition, table 1 shows the recent studies on LNG shipping problem using stochastic optimization algorithms and highlights the differences between the previous studies and the current research.

Table 1. The current study versus the earlier studies on LNG supply chain optimization

\begin{tabular}{lll}
\hline Author(s) & Stochastic Solution Algorithm & Mathematical model \\
\hline Morin et al., (2011) & Evolutionary search & MILP \\
Sayyaadi \& Babaelahi (2011) & Genetic algorithm NSGA-II & Multi-objective optimization \\
Tahouni et al., (2011) & Simulated Annealing & Nonlinear model \\
Stålhane et al. (2012b) & Multi-start local search & MIP \\
Goel et al., (2015) & Iterative search heuristic & Constraint programming \\
Agra et al., (2015) & $\begin{array}{l}\text { Sample average approximation } \\
\text { method }\end{array}$ & $\begin{array}{l}\text { Stochastic programming } \\
\text { model }\end{array}$ \\
Shao et al. (2015) & $\begin{array}{l}\text { Greedy randomized adaptive } \\
\text { search procedure (GRASP) }\end{array}$ & $\begin{array}{l}\text { Mixed integer programming } \\
\text { (MIP) }\end{array}$ \\
Al-Haidous et al. (2016) & Heuristic decomposition & MIP \\
Zhang et al., (2017) & Ant colony optimization & $\begin{array}{l}\text { Three-stage stochastic } \\
\text { programming }\end{array}$ \\
Msakni \& Haouari (2018) & Variable-neighborhood search & MIP \\
heuristic & Binary PSO & Nonlinear model \\
\hline
\end{tabular}

\section{Problem description and formulation}

\subsection{Problem description}

LNG, a green fuel, is a new source of energy that adapts to the environment, but its transfer is not as easy as other kinds of fuels. If a country or a company wishes to transfer LNG elsewhere, they should consider the distance; if it is short, it is preferable to transfer it by pipelines, but long 
distance the use of pipeline transfer is not possible and so vessels can help. Shipping causes some problems such as evaporation of LNG during the voyage, and when the amount of LNG is lower than that set in the contract and the buyer rejects it, it will cause many economic problems. Hence, finding the best route for shipping is vital. Although many problems can affect ship routing scheduling, many companies seek to decrease not only the time of shipping but also the related costs. These problems can be categorized based on the viewpoints of the buyers or sellers according to which the objective function and constraints of the problem will change; in this paper, the approach is based on the seller's viewpoint. Figure 1 illustrates a general scheme of the ship routing and scheduling of $\mathrm{LNG}$.

\begin{tabular}{|c|}
\hline $\begin{array}{c}\text { Liquefaction terminal } \\
\text { (Origin) }\end{array}$ \\
\hline
\end{tabular}

Shipping

Regasification terminal

(Destination)

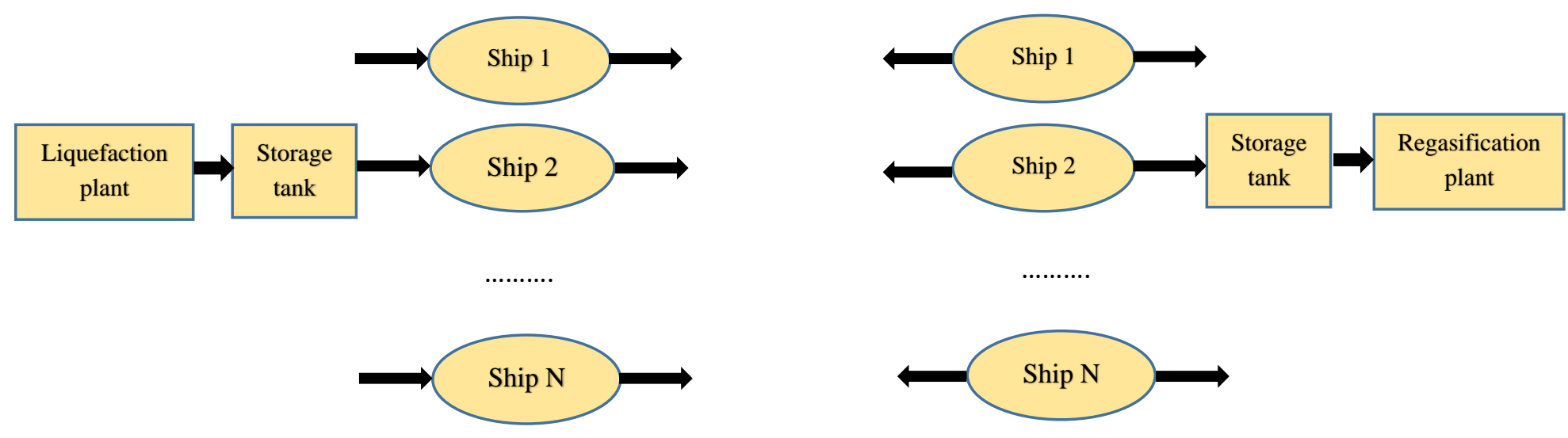

Seller

Buyer

Figure 1. An outline for the LNG shipping from seller to buyer

\subsection{Mathematical model}

We have developed a model based on the previous constraints and the LNG purchase agreement.

First, consider we have i sellers of LNG (where $1 \leq \mathrm{i} \leq \mathrm{n}$ ), each sells LNG to the buyer(s) which 
is represented by $\mathrm{j}$ and $\mathrm{j}^{\prime} 1 \leq \mathrm{j}, \mathrm{j}^{\prime} \leq \mathrm{n}$. Assume $\mathrm{v}$ shows the set of vessels which ships LNG from seller $\mathrm{i}$ to the buyer(s) $\mathrm{j}, \mathrm{j}^{\prime}$. Let's assume t denotes the period of time that vessel $\mathrm{v}$ carries LNG from seller i to the buyer(s) j, j'. In the port of origin, we have an inventory of LNG that is divided into three parts low, average and high levels of inventory that are represented as $\underline{I_{i j j^{\prime}}^{t}} I_{i j j^{\prime}}^{t}$ and $\overline{I_{\imath \jmath J^{\prime}}^{t}}$. The demand of buyers $\mathrm{j}, \mathrm{j}^{\prime}$ of LNG is revealed by $D_{\mathrm{ijj}}^{t}$.The problem has also involved with some costs including: the total cost of changing vessels, total cost of staff, total port unavailability penalty, total shipping maintenance costs, and the total LNG shipping delay penalty. These costs are indicated as $T P F V_{i j j^{\prime}}^{v t}, T H_{i j j^{\prime}}^{v t}, P T_{i j j^{\prime}}^{v t} T M_{i j j^{\prime}}^{v t}$ and $D E_{i j j^{\prime}}^{v t}$, respectively. Total time of shipping LNG is presented by $T O_{i j j^{\prime}}^{v t}$. Let's denote the probability of port unavailability in the destination, probability of ship failure during shipping and the probability of delivery delay during the shipping, respectively by $\int_{0}^{1} P O_{i j j^{\prime}}^{v t} \mathrm{dr}_{i}, \int_{0}^{1} P F_{i j j^{\prime}}^{v t} \mathrm{dr}_{i}$ and $\int_{0}^{1} P D_{i j j^{\prime}}^{v t} \mathrm{dr}_{i}$ that are in the form of stochastic data. The mentioned terms are probabilistic terms of occurring these events during the services. The variable $X_{i j j^{\prime}}^{v t}$ is the binary variable which shows if vessel v in time t from seller $\mathrm{i}$ goes to buyer(s) j, j' or not. The notations, parameters, and variables of the presented model are summarized as follows:

\section{Sets}

$$
\begin{array}{ccl}
i & : & \text { set of LNG sellers } \\
j, j^{\prime} & : & \text { set of LNG buyer(s) } \\
v & : & \text { set of vessels } \\
t & : & \text { set of time periods }
\end{array}
$$

\section{Parameters}

$I_{i j j^{\prime}}^{v t} \quad:$ Average LNG inventory level in the port of seller $i$ sent to buyer $j, j^{\prime}$ in time $t$ $\overline{I_{\imath J J^{\prime}}^{v t}}: \begin{aligned} & \text { The highest LNG inventory level in the port of seller } i \text { sent to buyer } j j, j^{\prime} \text { in } \\ & \text { time } t\end{aligned}$

$\underline{I_{i j j^{\prime}}^{v t}}$ : The lowest LNG inventory level in the port of seller i sent to buyer $\mathrm{j}, j^{\prime}$ in time $\mathrm{t}$

$L_{i j j^{\prime}}^{v t}:$ The quantity of LNG sent from seller $\mathrm{i}$ to buyer $\mathrm{j}, j^{\prime}$ by vessel $\mathrm{v}$ in time $\mathrm{t}$

$I N L_{i j j^{\prime}}^{t}:$ Amount of LNG sent from seller $\mathrm{i}$ to buyer $\mathrm{j}, j^{\prime}$ in time $\mathrm{t}$ before and available in the destination (port of buyer) in time $t$

$D_{\mathrm{ijj}}^{t} \quad: \quad$ Amount of LNG that buyer $\mathrm{j}, j^{\prime}$ wants from seller $\mathrm{i}$ in time $\mathrm{t}$ in the destination 
PFIV ${ }_{i j j^{\prime}}^{v}:$ Cost of changing vessels (for transportation of LNG) when seller i sends cargo to buyer $\mathrm{j}, j^{\prime}$ by vessel $\mathrm{v}$ in time $\mathrm{t}$

$T P F V_{i j j^{\prime}}^{v}:$ The total cost of changing vessels (for transportation of LNG) when seller $\mathrm{i}$ sends cargo to buyer $\mathrm{j}, j^{\prime}$ by vessel $\mathrm{v}$ in time $\mathrm{t}$

$H_{i j j^{\prime}}^{v} \quad$ : Cost of staff for transportation of LNG when seller i sends cargo to buyer $\mathrm{j}, j^{\prime}$ by vessel $\mathrm{v}$ in time $\mathrm{t}$

$T H_{i j j^{\prime}}^{v} \quad:$ The total cost of staff for transportation of LNG when seller i sends cargo to buyer $\mathrm{j}, j^{\prime}$ by vessel $\mathrm{v}$ in time $\mathrm{t}$

$T_{i j j^{\prime}}^{v t}:$ Time of shipping LNG when seller i sends cargo to buyer $\mathrm{j}, j^{\prime}$ by vessel $\mathrm{v}$ in time $\mathrm{t}$

$T O_{i j j^{\prime}}^{v t}$ : Total time of shipping LNG when seller i sends cargo to buyer $\mathrm{j}, j^{\prime}$ by vessel $\mathrm{v}$ in time $\mathrm{t}$

$P E P_{i j j^{\prime}}^{v t} \quad: \quad$ Port unavailability penalty for shipping LNG when seller i sends cargo to buyer $\mathrm{j}, j^{\prime}$ by vessel $\mathrm{v}$ in time $\mathrm{t}$

$P T_{i j j^{\prime}}^{v t}:$ Total port unavailability penalty for shipping LNG when seller i sends cargo to buyer $\mathrm{j}, j^{\prime}$ by vessel $\mathrm{v}$ in time $\mathrm{t}$

$M_{i j j^{\prime}}^{v}:$ LNG shipping maintenance costs when seller i sends cargo to buyer $\mathrm{j}, j^{\prime}$ by vessel $\mathrm{v}$ in time $\mathrm{t}$

$T M_{i j j^{\prime}}^{v} \quad$ : Total shipping maintenance costs when LNG is sent from seller i to buyer $\mathrm{j}, j^{\prime}$ by vessel $v$ in time $t$

$P D E_{i j j^{\prime}}^{v t} \quad$ : LNG shipping delay penalty when seller i sends cargo to buyer $\mathrm{j}, j^{\prime}$ by vessel v in time $\mathrm{t}$

$T P D E_{i j j^{\prime}}^{v t} \quad$ : Total LNG shipping delay penalty when seller i sends cargo to buyer $\mathrm{j}, j^{\prime}$ by vessel $\mathrm{v}$ in time $\mathrm{t}$

$\int_{0}^{1} P O_{i j j^{\prime}}^{v t} \mathrm{dr}: \begin{aligned} & \text { The probability of port unavailability in the destination when shipping LNG } \\ & \text { from seller } \mathrm{i} \text { to buyer } \mathrm{j}, j^{\prime} \text { by vessel } \mathrm{v} \text { in time } \mathrm{t}\end{aligned}$

$\int_{0}^{1} P F_{i j j^{\prime}}^{v t} \mathrm{dr}: \begin{aligned} & \text { The probability of ship failure during shipping LNG from seller } \mathrm{i} \text { to buyer } \mathrm{j}, j^{\prime} \\ & \text { by vessel v in time } \mathrm{t}\end{aligned}$

$\int_{0}^{1} P D_{i j j^{\prime}}^{v t} \mathrm{dr}: \quad \begin{aligned} & \text { The probability of delivery delay when shipping LNG from seller } \mathrm{i} \text { to buyer } \mathrm{j}, j^{\prime} \\ & \text { by vessel v in time } \mathrm{t}\end{aligned}$

\section{Variables}

$$
X_{i j j^{\prime}}^{v t}=\left\{\begin{array}{rc}
1, & \text { If the ship travels from seller i to buyer } \mathrm{j}, j^{\prime} \text { by vessel } \mathrm{v} \text { in time } \mathrm{t} \\
0, & \text { otherwise }
\end{array}\right.
$$




\section{Model}

$$
\begin{aligned}
\text { Min } Z=\sum_{i=1}^{n} & \sum_{j, j^{\prime} \in J}^{m} \sum_{t=1}^{k} \sum_{v=1}^{n} \int_{0}^{1} P O_{i j j^{\prime}}^{v t} \mathrm{dr}_{i} \times P T_{i j j^{\prime}}^{v t} \times X_{i j j^{\prime}}^{v t} \\
& +\sum_{i=1}^{n} \sum_{j, j^{\prime} \in J}^{m} \sum_{t=1}^{k} \sum_{v=1}^{n} X_{i j j^{\prime}}^{v t} \times T H_{i j j^{\prime}}^{v} \\
& +\sum_{i=1}^{n} \sum_{j, j^{\prime} \in J}^{m} \sum_{t=1}^{k} \sum_{v=1}^{n} \int_{0}^{1} P F_{i j j^{\prime}}^{v t} \mathrm{dr}_{i} \times T P F V_{i j j^{\prime}}^{v} \times X_{i j j^{\prime}}^{v t} \\
& +\sum_{i=1}^{n} \sum_{j, j^{\prime} \in J}^{m} \sum_{t=1}^{k} \sum_{v=1}^{n} X_{i j j^{\prime}}^{v t} \times T M_{i j j^{\prime}}^{v} \\
& +\sum_{i=1}^{n} \sum_{j, j^{\prime} \in J}^{m} \sum_{t=1}^{k} \sum_{v=1}^{n} \int_{0}^{1} P D_{i j j^{\prime}}^{v t} \mathrm{dr}_{i} \times T P D E_{i j j^{\prime}}^{v} \times X_{i j j^{\prime}}^{v t}
\end{aligned}
$$

The objective function (Eq. 1) seeks for minimizing the cost of shipping based on stochastic parameters including probability of port unavailability, probability of ship failure, probability of delay on delivery and deterministic parameters including total cost of staff, cost of changing ship, maintenance cost and penalty of delay when ship goes or not.

s.t:

$\underline{I_{i j j^{\prime}}^{t}} \leq \sum_{v=1}^{n} X_{i j j^{\prime}}^{v t} \times I_{\mathrm{ijj}}^{t} \leq \overline{I_{l \jmath j^{\prime}}^{t}} \quad \forall \mathrm{i} \in \mathrm{I}, \mathrm{j}, \mathrm{j}^{\prime} \in \mathrm{J}, \mathrm{t} \in \mathrm{T}$

The first constraint (Eq. 2) ensures the volume of inventory in the destination port considering a window of inventory. This constraint is needed considering the constant rate of LNG evaporation per day.

$$
L_{i j j^{\prime}}^{v t} \times X_{i j j^{\prime}}^{v t}+I N L_{i j j^{\prime}}^{t} \geq D_{\mathrm{ijj}}^{t} \quad \forall \mathrm{i} \in \mathrm{I}, \mathrm{j}, \mathrm{j}^{\prime} \in \mathrm{J}, \mathrm{t} \in \mathrm{T}, \mathrm{v} \in \mathrm{V}
$$

The second constraint (Eq. 3) guarantees that the demand of the customer will be satisfied. This constraint is necessary to because the seller needs to satisfy all the demand of the buyer considering the inventory in the latter's port. 
$L_{i j j^{\prime}}^{v t} \times X_{i j j^{\prime}}^{v t} \leq I_{\mathrm{ijj} j^{\prime}}^{t} \quad \forall \mathrm{i} \in \mathrm{I}, \mathrm{j}, \mathrm{j}^{\prime} \in \mathrm{J}, \mathrm{t} \in \mathrm{T}, \mathrm{v} \in \mathrm{V}$

The third considered constraint (Eq. 4) ensures lower or equal inventory in the destination port.

$\int_{0}^{1} P O_{i j j^{\prime}}^{v t} \mathrm{dr}_{\mathrm{i}} \times X_{i j j^{\prime}}^{v t} \times P E P_{i j j^{\prime}}^{v t} \leq P T_{i j j^{\prime}}^{v t} \quad \forall \mathrm{i} \in \mathrm{I}, \mathrm{j}, \mathrm{j}^{\prime} \in \mathrm{J}, \mathrm{t} \in \mathrm{T}, \mathrm{v} \in \mathrm{V}$

In order to consider the port availability of buyer and seller, the fifth constraint (Eq. 5), evaluates the probability of berth availability as well as the penalty of its unavailability.

$H_{i j j^{\prime}}^{v t} \times X_{i j j^{\prime}}^{v t} \leq T H_{i j j^{\prime}}^{v t} \quad \forall \mathrm{i} \in \mathrm{I}, \mathrm{j}, \mathrm{j}^{\prime} \in \mathrm{J}, \mathrm{t} \in \mathrm{T}, \mathrm{v} \in \mathrm{V}$

Sixth constraint (Eq. 6) considers the cost of human resources and staff of the ship which is an important element for both LNG seller and buyer.

$T_{i j}^{v t} \times X_{i j}^{v t}+X_{j j^{\prime}}^{v t} \times T_{j j^{\prime}}^{v t} \leq T O_{i j j^{\prime}}^{v t} \quad \forall \mathrm{i} \in \mathrm{I}, \mathrm{j}, \mathrm{j}^{\prime} \in \mathrm{J}, \mathrm{t} \in \mathrm{T}, \mathrm{v} \in \mathrm{V}$

Seventh constraint (Eq. 7) shows the voyage time and ensures that each ship should go from the seller port and return to the destination after delivering LNG to one or some buyers.

$\int_{0}^{1} P F_{i j j^{\prime}}^{v t} d r_{i} \times P F I V_{i j j^{\prime}}^{v} \times X_{i j j^{\prime}}^{v t} \leq T P F V_{i j j^{\prime}}^{v} \quad \forall \mathrm{i} \in \mathrm{I}, \mathrm{j}, \mathrm{j}^{\prime} \in \mathrm{J}, \mathrm{t} \in \mathrm{T}, \mathrm{v} \in \mathrm{V}$

The probability of ship failure during the shipping process, costs of changing ships, related penalties, and reserving ships are considered in the eighth constraint (Eq. 8). From a buyer point of view, this is a very important factor to guarantee the on-time delivery of LNG.

$M_{i j j^{\prime}}^{v} \times X_{i j j^{\prime}}^{v t} \leq T M_{i j j^{\prime}}^{v} \quad \forall \mathrm{i} \in \mathrm{I}, \mathrm{j}, \mathrm{j}^{\prime} \in \mathrm{J}, \mathrm{t} \in \mathrm{T}, \mathrm{v} \in \mathrm{V}$

The ninth constraint (Eq. 9) considers the ship maintenance costs. 


$$
\int_{0}^{1} P D_{i j j^{\prime}}^{v t} \mathrm{dr}_{\mathrm{i}} \times P D E_{i j j^{\prime}}^{v t} \times X_{i j j^{\prime}}^{v t} \leq T P D E_{i j j^{\prime}}^{v t} \quad \forall \mathrm{i} \in \mathrm{I}, \mathrm{j}, \mathrm{j}^{\prime} \in \mathrm{J}, \mathrm{t} \in \mathrm{T}, \mathrm{v} \in \mathrm{V}
$$

Finally, the tenth constraint (Eq. 10) deals with delivery delays and the related penalties.

Although many papers and contracts consider delivery time window, this paper has added this time window to the tolerance time and then has calculated the delay probability together with the LNG delivery time after tolerance time. In the objective function, the ship routing costs are decreased based on the port unavailability costs, staff costs, delayed delivery costs, maintenance costs, and ship changing costs when it fails to work.

\subsection{Assumptions}

The following assumptions are considered in the model which are as follows:

1. In the first day, all ships are in the origin berth.

2. All demands are based on annual delivery programs

3. All ships load cargo and go to their destinations.

4. The weather condition has no effects on the transportation of ships.

\section{Solution approach}

The proposed model in section 3.2 is solved by a BPSO algorithm. First, we introduce some required concept of the BPSO approach and then we elaborate on the solving procedure of the model.

\subsection{BPSO algorithm}

The meta-heuristic PSO algorithm (Kennedy and Eberhart, 1995), has been proposed based on the fish and bird behavior and uses the population generation and movement of particles to find the best solution (space) considering velocity. Since traditional PSO is suitable for continuous space, Kennedy and Eberhart (1997) developed the BPSO algorithm which is mainly applicable in discrete spaces. The BPSP can better solve the stochastic NP-hard problems, specifically when we face binary variables and parameters in the optimization problems (Liu \& Fan, 2009; Zhang et al. 2014).

The reason why BPSO has been used in this research is that it deals with the stochastic data and the binary variable in the presented model and it is a reasonable solution. Moreover, BPSO attempts to satisfy all the constraints. If it cannot, it will balance a tradeoff between the number of constraints and the objective function. Its other advantages are: i) it is easily coded, ii) it has the powerful searching ability, iii) its solution has less sensitivity compared to other methods, iv) it 
depends less on the initial points, and v) it generates high-quality solutions in shorter time intervals and with fewer calculations.

\subsection{Solving procedure}

In this research, the problem-solving procedure is as follows:

1. Creating the model: first, the mathematical model is created based on the real-world data.

2. Finding the best solution: after studying different solution methods, BPSO is selected as the best algorithm. Figure 2 depicts the procedure of finding the optimal solution via the BPSO algorithm.

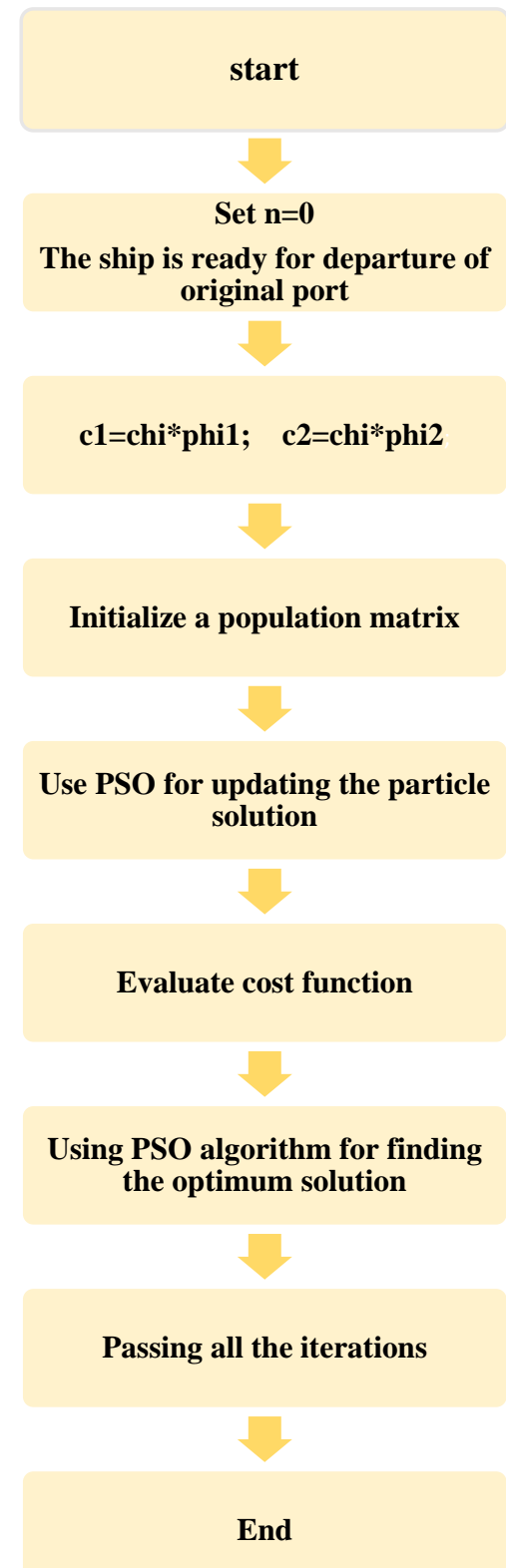

Figure 2. The procedure for finding the optimal solution 
3. Methodology: the problem-solving methodology is based on penalty functions; we add constraints to the objective function and add violation for each constraint. The Eq. 11 to 16 show how this mathematical concept helps us to solve this problem.

$\operatorname{Min} \mathrm{f}(\mathrm{x})$

S.t:

$$
g_{i}(x) \geq 0 \quad i=1,2, \ldots, n
$$

Therefore, we have:

$$
\operatorname{Min} \mathrm{f}(\mathrm{x})=\sum_{i=1}^{n} \lambda_{i} \times g_{i}
$$

Equation 13 indicates the violation function in its mathematical form as below:

$$
\begin{aligned}
& \mathrm{G}(\mathrm{x}) \geq g_{0} \\
& \mathrm{~V}\left\{\mathrm{~g}(\mathrm{x}) \geq g_{0}\right\}= \begin{cases}0 & g(x) \leq g_{0} \\
1-\frac{g(x)}{g_{0}} & g(x)<g_{0}\end{cases} \\
& \mathrm{G}(\mathrm{x}) \leq g_{0} \\
& \mathrm{~V}\left\{\mathrm{~g}(\mathrm{x}) \leq g_{0}\right\}= \begin{cases}\frac{g(x)}{g_{0}}-1 & g(x) \geq g_{0}\end{cases}
\end{aligned}
$$

In the Eq. 13, V corresponds to the objective function violation. V controls the amount of violation from the optimal solution. Actually, this term lets the algorithm search for the solution within the boundary and avoid going beyond the acceptable deviation from the feasible boundary.

In this work, there are three types of penalty functions:

A. Additive penalty function

B. $\hat{f}(x)=f(x)+\alpha * \mathrm{P}(\mathrm{v})$

S.t:

$\mathrm{v} \geq 0$ 
C. Multiplicative penalty function

$$
\hat{f}(x)=f(x)\left(1+\beta^{*} \mathrm{P}(\mathrm{v})\right) \quad \forall f(x) \geq 0
$$

s.t:

$\mathrm{v} \geq 0$

D. The hybrid additive-multiplicative penalty function

$$
\begin{aligned}
& \widehat{f_{1}}(x)=\left(f(x)+\alpha^{*} \mathrm{P}(\mathrm{v})\right)\left(1+\beta^{*} \mathrm{Q}(\mathrm{v})\right) \\
& \widehat{f^{f_{2}}}(x)=\left(f(x)\left(1+\beta^{*} \mathrm{Q}(\mathrm{v})\right)+\alpha * P(v)\right. \\
& \text { s.t: } \\
& v \geq 0
\end{aligned}
$$

4. Sensitivity analysis: this model will be run for a diverse number of ships to provide a comprehensive sensitivity analysis.

\section{Computational experiments}

In this study, a numerical example is solved to test the robustness and reliability of the proposed model and the applied solution approach. We proceeded based on the four-step solving procedure explained in section 4.2. At the first stage, we created the mathematical model presented in section 3.2 and gathered real data for it. Data were semi-real and semi-artificial. First, boundaries of each constraint were found based on real data and then the data were generated based on the random generation order in the MATLAB software. Appendix A shows a sample of the generated data for the constraints of the proposed model. The source of data was extracted from Rakke et al. (2011) study. Based on the Rakke et al. (2011) dataset and other contracts, some data were as follows:
a) Price of LNG is 150 USD per $\mathrm{m}^{3}$ (fixed)
b) Penalty cost is 25 USD per $\mathrm{m}^{3}$ for each month
c) Penalty cost for unavailability of the berth is 1,0000 USD per day
d) Cost of maintenance is 100,000 USD per day
e) Average staff cost is 6,000 USD per month per person
f) Average ship changing cost is $1,000,000$ USD 
Based on the long-term contract, we solved the model for several volumes of the request. Following steps 2 and 3 (finding the best solution and methodology), a scenario-based BPSO method was coded to solve the ship routing and scheduling of LNG. Accordingly, the model was run as follows:

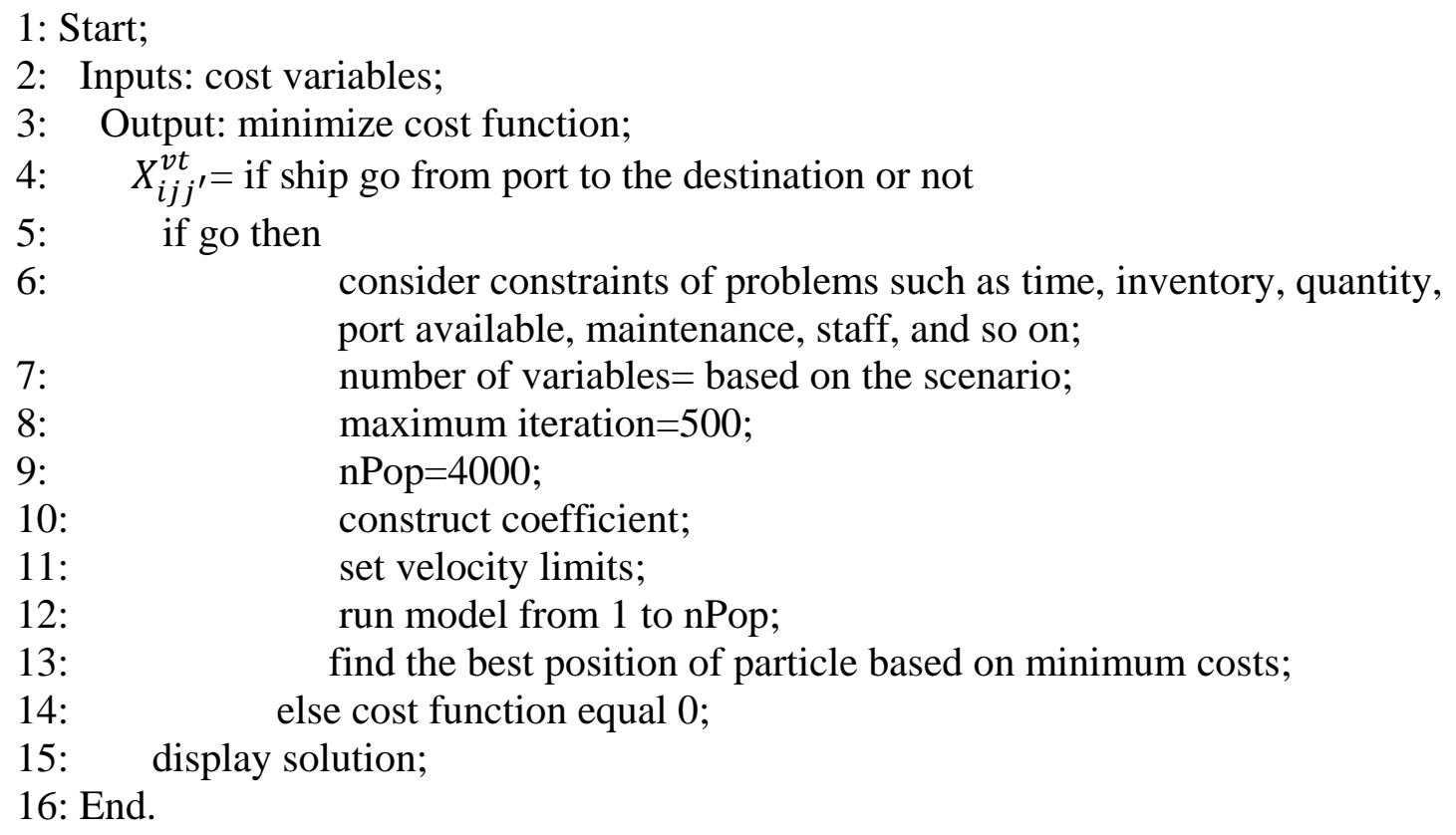

This model was run by MATLAB 2015b; PC: CPU Corei3 and RAM 2 G. Following the fourth step, for sensitivity analysis, scenario-based optimization used for finding the solution. We used 6 scenarios for coding the BPSO algorithm by a different number of ships. We considered the number of ships 10, 100, 200, 300, 400 and 500 for running the scenarios. The results are shown in Table 2.

Table 2. Solving problems considering different scenarios

\begin{tabular}{cccc}
\hline Scenario & $\begin{array}{c}\text { Number of } \\
\text { ships }\end{array}$ & Cost function (\$) & Time (S) \\
\hline 1 & 10 & $1,008,596,0384,911$ & 425.49 \\
2 & 100 & $5,659,428,075,056$ & 449.51 \\
3 & 200 & $3,510,360,739,829$ & 497.13 \\
4 & 300 & $1,521,982,239,885$ & 482.376 \\
5 & 400 & $1,251,502,223,787$ & 506.68 \\
6 & 500 & $866,419,470,369$ & 493.16 \\
\hline
\end{tabular}


Based on the obtained results from 6 scenarios, the relationship between the cost function and the number of ships is depicted in figure 3.

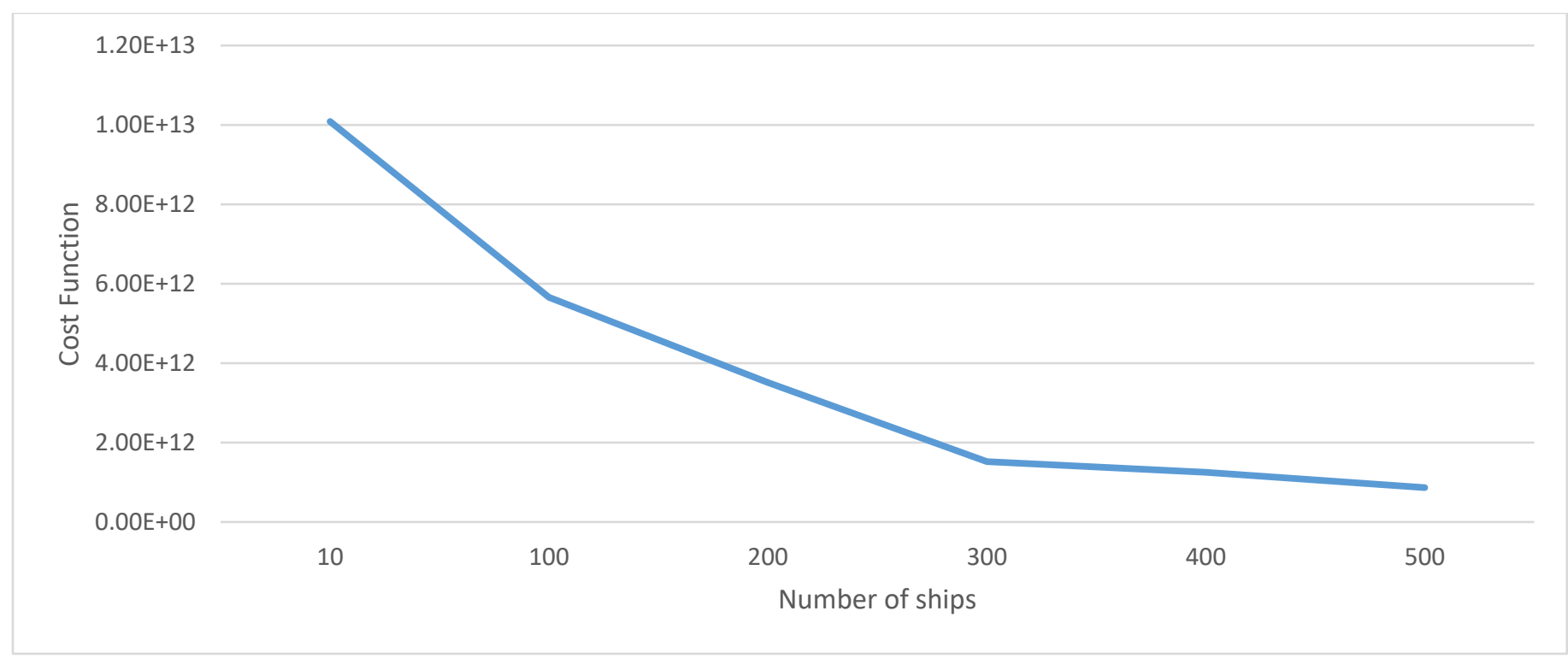

Figure 3. The relationship between cost function and the number of ships

Figure 4 demonstrates the relationship between the solution time and the number of ships

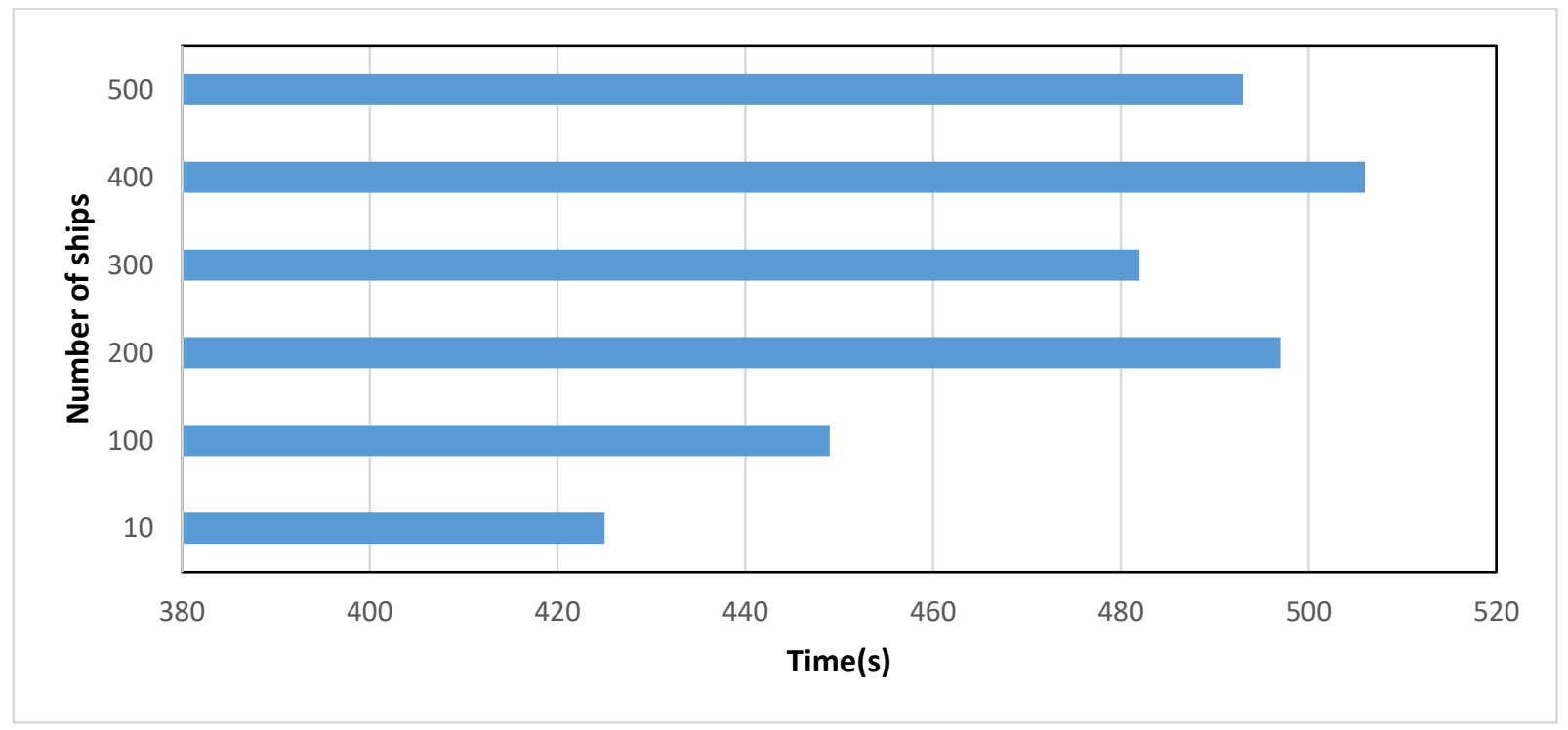

Figure 4. The relationship between time and number of ships 
Figures 5 depicts the relationships among the best cost considering a different number of ships.

10 ships
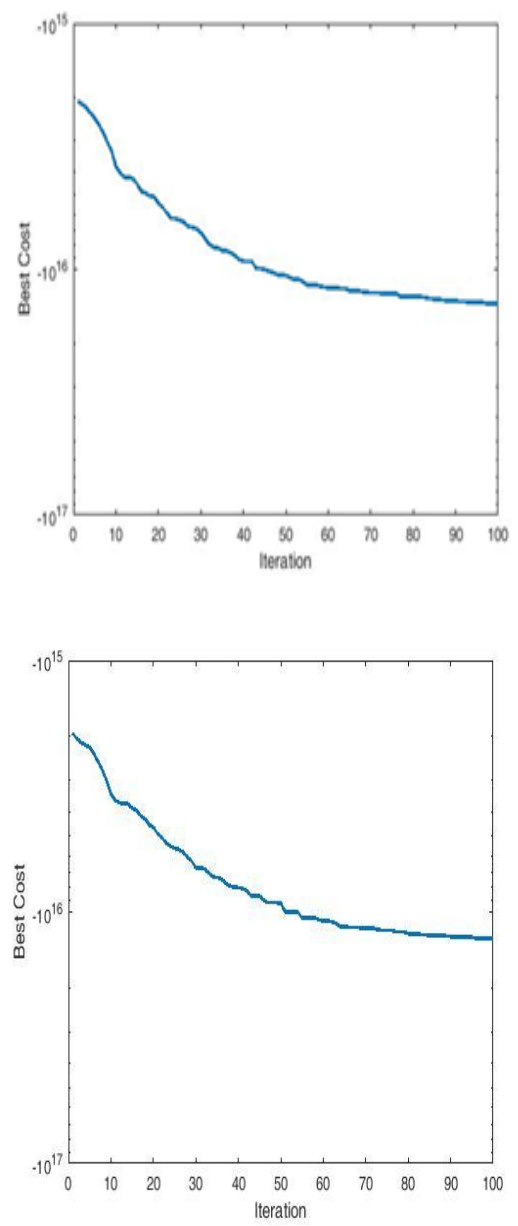

300 ships
100 ships
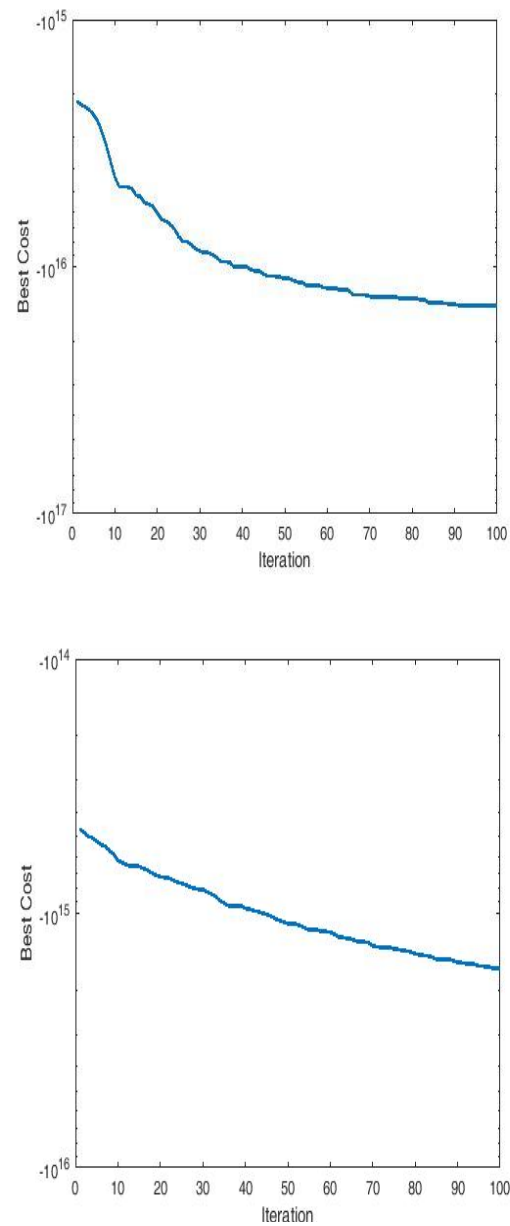

400 ships
200 ships
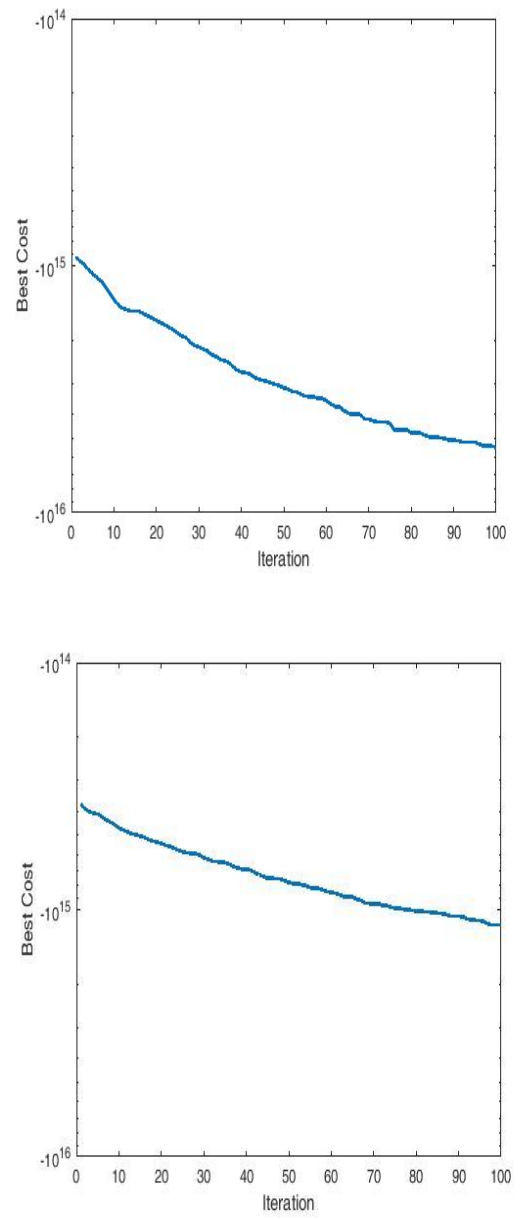

500 ships

Figure 5. The relationship between best cost and iterations considering different ships

Figure 5 shows six cases related to the relationships between the best costs and the iterations in different scenarios. With 10 ships, the number of iterations is low for achieving the optimal. Considering 100 ships, the iterations to the optimal solution are increased. This event is repeated where the number of ships is 200. The number of iterations for finding the optimal solution with 300 ships compared to the situation of with 200 ships. In the cases, 400 and 500 
ships, the number of ships increases, nonetheless, the iterations for reaching the optimal cost is decreased.

\section{Concluding remarks}

In today's global energy systems, the LNG consumption rate is increasing rapidly since its more environmental friendly (it is a green fuel) while other fuels such as crude oil, coal, so on, are not. Effective ship routing and scheduling play a key role to reduce the cost of fuel supply and feeding $\mathrm{LNG}$, as a green fossil fuel, to manufacturing companies is a challenging issue for the manufacturers. LNG production needs considerable investigations for its extraction, transportation, and regasification. As a result, a ship routing and scheduling model to supply LNG is formulated in this paper. Although researches about this kind of problems are not many, most of them have attempted to develop a new method for finding not only the best solution but also taking the less time for computation. In previous researches, Rakke et al. (2011) have used heuristic methods to find exact solutions. In their research, Halvorsen-Weare et al. (2013) have used simulation to change uncertain environments into certain ones. Goel et al. (2015) have made use of the CPLEX software to solve this problem. In this research, MATLAB software with one metaheuristic method, called BPSO, has been used for solving this problem. Results have shown that despite the large problem size, cost factor will decrease, but the problem-solving time will increase with an increase in the number of variables.

For future studies, this model can be applied to other productions because they have specific transportation situations. In addition, this model can be solved through such other methods as Differential Evolutionary, Genetic Algorithm, Tabu Search, and various heuristic and metaheuristic methods. Another suggestion for future researches is considering some options and adding them to the constraints. This model can be also extended to a multi-objective optimization problem.

\section{References}

Austbø, B., Løvseth, S. W., \& Gundersen, T. (2014). Annotated bibliography-Use of optimization in LNG process design and operation. Computers \& Chemical Engineering, 71, 391-414.

Agra, A., Christiansen, M., Delgado, A., \& Hvattum, L. M. (2015). A maritime inventory routing problem with stochastic sailing and port times. Computers \& Operations Research, 61, 18-30.

Al-Haidous, S., Msakni, M. K., \& Haouari, M. (2016). Optimal planning of liquefied natural gas deliveries. Transportation Research Part C: Emerging Technologies, 69, 79-90. 
Andersson, H., Christiansen, M., \& Fagerholt, K. (2010). Transportation planning and inventory management in the LNG supply chain. In Energy, natural resources and environmental economics (pp. 427-439). Springer Berlin Heidelberg.

Andersson, H., Christiansen, M., Desaulniers, G., \& Rakke, J. G. (2017). Creating annual delivery programs of liquefied natural gas. Optimization and Engineering, 18(1), 299-316.

Beheshti, Z., Shamsuddin, S. M., \& Hasan, S. (2015). Memetic binary particle swarm optimization for discrete optimization problems. Information Sciences, 299, 58-84.

Berle, Ø., Norstad, I., \& Asbjørnslett, B. E. (2013). Optimization, risk assessment and resilience in LNG transportation systems. Supply Chain Management: An International Journal, 18(3), 253-264.

Biobaku, T., Lim, G., Cho, J., Parsaei, H., \& Kim, S. (2015). Liquefied natural gas ship route planning: A risk analysis approach. Procedia Manufacturing, 3, 1319-1326.

Christiansen, M., Fagerholt, K., Nygreen, B., \& Ronen, D. (2013). Ship routing and scheduling in the new millennium. European Journal of Operational Research, 228(3), 467-483.

EIA, U. (2009). Annual Energy Review: 2008. Energy Information Administration. DOE/EIA-0384 (2008) http://www. eia. doe. gov/aer/pdf/aer. pdf. Accessed 30 June.

Goel, V., Furman, K. C., Song, J. H., \& El-Bakry, A. S. (2012). Large neighborhood search for LNG inventory routing. Journal of Heuristics, 18(6), 821-848.

Goel, V., Slusky, M., van Hoeve, W. J., Furman, K. C., \& Shao, Y. (2015). Constraint programming for LNG ship scheduling and inventory management. European Journal of Operational Research, 241(3), 662-673.

Ghiami, Y., Van Woensel, T., Christiansen, M., \& Laporte, G. (2015, September). A combined liquefied natural gas routing and deteriorating inventory management problem. In International Conference on Computational Logistics (pp. 91-104). Springer, Cham.

Gkonis, K. G., \& Psaraftis, H. N. (2009). The LNG market: a game theoretic approach to competition in LNG shipping. Maritime economics \& logistics, 11(2), 227-246.

Grønhaug, R., \& Christiansen, M. (2009). Supply chain optimization for the liquefied natural gas business. In Innovations in distribution logistics (pp. 195-218). Springer Berlin Heidelberg.

Grønhaug, R., Christiansen, M., Desaulniers, G., \& Desrosiers, J. (2010). A branch-and-price method for a liquefied natural gas inventory routing problem. Transportation Science, 44(3), 400-415.

Halvorsen-Weare, E. E., \& Fagerholt, K. (2013). Routing and scheduling in a liquefied natural gas shipping problem with inventory and berth constraints. Annals of Operations Research, 203(1), 167-186.

Halvorsen-Weare, E. E., Fagerholt, K., \& Rönnqvist, M. (2013). Vessel routing and scheduling under uncertainty in the liquefied natural gas business. Computers \& Industrial Engineering, 64(1), 290-301.

Hartley, P. R., Mitchell, G., Mitchell, C., \& Baker, J. A. (2013). The future of long-term LNG contracts. University of Western Australia Business School. Economics.

Jain, I., Jain, V. K., \& Jain, R. (2018). Correlation feature selection based improved-Binary Particle Swarm Optimization for gene selection and cancer classification. Applied Soft Computing, 62, 203-215.

Kennedy, J., \& Eberhart, R. (1995). Proceedings of IEEE international conference on neural networks. Perth, Australia.

Kennedy, J., \& Eberhart, R. C. (1997, October). A discrete binary version of the particle swarm algorithm. In Systems, Man, and Cybernetics, 1997. Computational Cybernetics and Simulation., 1997 IEEE International Conference on (Vol. 5, pp. 4104-4108). 
Khalilpour, R., \& Karimi, I. A. (2011). Selection of liquefied natural gas (LNG) contracts for minimizing procurement cost. Industrial \& engineering chemistry research, 50(17), 10298-10312.

Koza, D. F., Ropke, S., \& Molas, A. B. (2017). The liquefied natural gas infrastructure and tanker fleet sizing problem. Transportation Research Part E: Logistics and Transportation Review, 99, 96-114.

Liu, J., \& Fan, X. (2009, December). The analysis and improvement of binary particle swarm optimization. In Computational Intelligence and Security, 2009. CIS'09. International Conference on (Vol. 1, pp. 254-258). IEEE.

Morin, A., Wahl, P. E., \& Mølnvik, M. (2011). Using evolutionary search to optimise the energy consumption for natural gas liquefaction. Chemical Engineering Research and Design, 89(11), 24282441.

Massol, O., \& Tchung-Ming, S. (2010). Cooperation among liquefied natural gas suppliers: Is rationalization the sole objective?. Energy Economics, 32(4), 933-947.

Msakni, M. K., \& Haouari, M. (2018). Short-term planning of liquefied natural gas deliveries. Transportation Research Part C: Emerging Technologies, 90, 393-410.

Mutlu, F., Msakni, M. K., Yildiz, H., Sönmez, E., \& Pokharel, S. (2016). A comprehensive annual delivery program for upstream liquefied natural gas supply chain. European Journal of Operational Research, 250(1), 120-130.

Rakke, J. G., Stålhane, M., Moe, C. R., Christiansen, M., Andersson, H., Fagerholt, K., \& Norstad, I. (2011). A rolling horizon heuristic for creating a liquefied natural gas annual delivery program. Transportation Research Part C: Emerging Technologies, 19(5), 896-911.

Sayyaadi, H., \& Babaelahi, M. (2011). Multi-objective optimization of a joule cycle for re-liquefaction of the Liquefied Natural Gas. Applied energy, 88(9), 3012-3021.

Shao, Y., Furman, K. C., Goel, V., \& Hoda, S. (2015). A hybrid heuristic strategy for liquefied natural gas inventory routing. Transportation Research Part C: Emerging Technologies, 53, 151-171.

Skaugen, G., Walnum, H. T., Hammer, M., Wahl, P. E., Wilhelmsen, Ø., \& Kolsaker, K. (2013). Design and optimization of compact heat exchangers in processes used for liquefaction of natural gas. In Unpublished paper at International Conference of Applied Energy (ICAE).

Stålhane, M., Rakke, J. G., Moe, C. R., Andersson, H., Christiansen, M., \& Fagerholt, K. (2012). A construction and improvement heuristic for a liquefied natural gas inventory routing problem. Computers \& Industrial Engineering, 62(1), 245-255.

Tahouni, N., Panjeshahi, M. H., \& Ataei, A. (2011). Comparison of sequential and simultaneous design and optimization in low-temperature liquefaction and gas separation processes. Journal of the Franklin Institute, 348(7), 1456-1469.

Yang, J., Zhang, H., Ling, Y., Pan, C., \& Sun, W. (2014). Task allocation for wireless sensor network using modified binary particle swarm optimization. IEEE Sensors Journal, 14(3), 882-892.

Zhang, H., Liang, Y., Liao, Q., Yan, X., Shen, Y., \& Zhao, Y. (2017). A three-stage stochastic programming method for LNG supply system infrastructure development and inventory routing in demanding countries. Energy, 133, 424-442.

Zhang, C., Nemhauser, G., Sokol, J., Cheon, M. S., \& Keha, A. (2018). Flexible solutions to maritime inventory routing problems with delivery time windows. Computers \& Operations Research, 89, 153162. 


\section{Appendix A}

A sample of MATLAB code for generating data for the equations 2 to 10 of the proposed model is as follows:

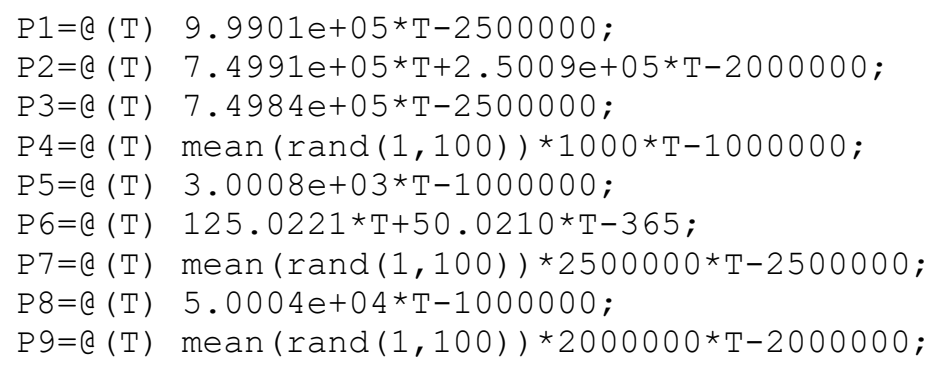

